\title{
Autonomy-control variation in child rearing and neurotic tendency in young adults: An exploratory study
}

\author{
ANTON F. de MAN \\ Bishop's University, Lennoxville, Quebec JIM 1Z7, Canada
}

and

\author{
LAWRENCE WEINSTEIN \\ St. Leo College, St. Leo, Florida 33574
}

\begin{abstract}
A total of 36 young adults participated in an exploratory investigation examining the relationship between autonomy-control variation in child rearing and neurotic tendency. Results disclosed that subjects of the autonomy group displayed lower neurotic tendencies than subjects of the intermediate group.
\end{abstract}

Most human beings function in an environment that on many occasions threatens their efforts toward maintenance and actualization and, as such, taxes their adjustive capacity. While some are able to meet almost every challenge, there are others who are unable to cope satisfactorily. In these people, the threatening circumstances may elicit anxiety that in turn demands some protective action. This may lead to the display of behaviors that have been labeled neurotic.

While the concept of neurosis encompasses a wide range of behaviors, the basic entity is a maladaptive life-style, characterized by feelings of threat and anxiety in facing the problems of everyday life, coupled with attempts to deal with this anxiety by means of defenseoriented avoidance behavior. In this investigation, it is speculated that particular parent-child relationships are, among other factors, at the base of this maladaptive life-style, displayed in later life. Schaefer $(1959,1965)$ suggests that parent-child relationships vary along two major dimensions, namely autonomy vs. control, which reflects the level of control exercised by the parents, and love vs. hostility, which refers to the emotional aspect of the parent-child interaction. Focusing on the first dimension, it is possible that a child who, due to the controlling attitude of his parents, is not allowed to experiment with a wide variety of roles and social situations may fail to acquire needed competencies and coping behaviors, thus rendering him more vulnerable later in life than a child coming from an autonomyoriented family background would be.

In this context, this study purposes to explore whether variation along the autonomy-control dimension relates in any systematic way to neurotic tendencies in young adults. No attempt was made at examining the love-hostility dimension discussed above; moreover, informal observation might lead one to believe that the subjects felt accepted and loved by their parents.

\section{METHOD}

\section{Subjects}

Professionals who in the course of their work are in the position to evaluate family backgrounds were requested to nominate middle-class (Blishen's, 1967, socio-economic index, pp. 44-50) young adults who came from intact (no divorce) families that came close to fitting either one of two family descriptions that were supplied as guidelines (the guidelines covered practices such as the extent to which parents cater to the wishes of the child, resolve conflict between wants of the child and their own, force the child to do things against his will, supervise play activities and selection of friends, etc.). In addition, the professionals were asked to nominate individuals coming from "intermediate" families.

The participants were 36 white middle-class young adults ranging in age from 20 to 30 years. Twelve subjects came from families characterized by autonomy, 12 from an intermediate background, and 12 from an environment characterized by control. Males and females were equally represented in each group.

\section{Dependent Measure}

The Neuroticism Scale Questionnaire (NSQ) (Scheier \& Cattell, 1961) was selected as the instrument for the measurement of degrees of neuroticism or neurotic trend. The authors of the questionnaire maintain that some degree of neurosis exists in every individual. As such, the questionnaire is intended to discriminate not only between neurotics and normals, but also between varying degrees of slightly neurotic trend in persons usually classed as normal.

\section{RESULTS}

The dependent variable, the NSQ, was analyzed by analysis of variance. In the NSQ high scores indicate high neuroticism and low scores mean lower neurotic levels. A 2 by 3 analysis of variance (two levels of sex of subject, three levels of parental limit setting: autonomy, intermediate, control) performed on the total scores of the NSQ disclosed a main effect of autonomycontrol variation $[F(2,30)=7.328, p<.005]$. The 
Duncan multiple-range test (DMRT) indicated that subjects of the autonomy group showed significantly fewer neurotic tendencies than the subjects of the intermediate group $(\mathrm{p}<.05)$, with all other groups being equal to each other. The autonomy mean was 35.08 , and the intermediate group mean was 46.25 .

\section{DISCUSSION}

An explanation for these findings is sought in the suggestion that parental limit setting influences the development of the individual's reality, possibility, and value assumptions, which together constitute the frame of reference with which he interacts with his environment. Children coming from an autonomyoriented background apparently have had sufficient chance to experiment with various roles, social situations, and values and have been placed in the position to build a broad frame of reference with which they are ready to interact with their environment and with others in their environment. They are flexible in their expectations of life and do not have to face excessive ambiguity, uncertainty, and anxiety. Their neurotic tendencies will be low.

The people in the intermediate group experienced a level of control that allowed them to develop a frame of reference with which they are able to participate in society to a certain extent. It is, however, not characterized by the completeness and flexibility that may be observed in the subjects of the autonomy group. As a result, the intermediate subjects may be faced with a certain amount of ambiguity, uncertainty, and conflict in dealing with their environment, which may lead to increase in neurotic tendency.

So far, the discussion has restricted itself to the findings of a
DMRT at $\mathrm{p}<.05$, which did not reveal any significant findings regarding any of the other comparisons (autonomy vs. control, intermediate vs. control). If one is willing to accept the results of a DMRT at $p<.10$, showing significant differences between the means involved in all three comparisons (autonomy, 35.08; intermediate, 46.25; control, 40.83), then some speculation becomes possible with respect to this aspect. The significance $(p<.10)$ of each comparison indicates that the relationship between autonomy-control variation and neurotic tendency is not a linear one. Apparently, subjects of the control group show a higher level of neurotic tendency than those of the autonomy group, but a lower level than the intermediates. It might be hypothesized that the control subjects have developed a narrow frame of reference, but that, at the same time, they function in a very narrow segment of society. They may indeed be limited in their contacts with society, but at the same time, a great deal of uncertainty in their lives may have been eliminated.

\section{REFERENCES}

Buishen, B. R. A socio-economic index for occupations in Canada. Canadian Review of Sociology and Anthropology, 1967, 4, 41-53.

Schaefer, E. S. A circumplex model for maternal behavior. Journal of Abnormal and Social Psychology, 1959, 59, 226-235.

SchaEfer, E. S. A configurational analysis of children's reports of parent behavior. Journal of Consulting Psychology, 1965, 29, 552-557.

SCheier, J. H., \& CATtell, R. B. Handbook for the Neuroticism Scale Questionnaire. Champaign, Ill: Institute for Personality and Ability Testing, 1961.

(Received for publication March 10, 1981.) 